\title{
Nematicidal Activity of 5-Hydroxymethyl-2-furoic Acid against Plant-Parasitic Nematodes
}

\author{
Yasuo Kimura ${ }^{\text {a }}$, Satoko Tani ${ }^{\mathrm{a}}$, Asami Hayashi ${ }^{\mathrm{a}}$, Kouhei Ohtani ${ }^{\mathrm{a}}$, Shozo Fujioka ${ }^{\mathrm{b}}$, \\ Tsuyoshi Kawano ${ }^{a}$, and Atsumi Shimadac,* \\ a Department of Biological and Environmental Chemistry, Faculty of Agriculture, \\ Tottori University, Koyama, Tottori, Tottori 680-8553, Japan \\ b RIKEN (The Institute of Physical and Chemical Research), 2-1 Hirosawa, Wako-shi, \\ Saitama 351-0198, Japan \\ c Department of Food and Nutrition, Faculty of Food and Nutrition Science, \\ Beppu University, 82 Kita-ishigaki, Beppu, Oita 874-8501, Japan. \\ E-mail: shimada@nm.beppu-u.ac.jp \\ * Author for correspondence and reprint requests \\ Z. Naturforsch. 62 c, 234-238 (2007); received September 15/October 20, 2006 \\ A nematicide, 5-hydroxymethyl-2-furoic acid (1), was isolated from cultures of the fungus \\ Aspergillus sp. and its structure was identified by spectroscopic analysis. Compound $\mathbf{1}$ showed \\ effective nematicidal activities against the pine wood nematode Bursaphelenchus xylophilus \\ and the free-living nematode Caenorhabditis elegans without inhibitory activity against plant \\ growth, but 1 did not show any effective nematicidal activity against Pratylenchus penetrans. \\ Key words: 5-Hydroxymethyl-2-furoic Acid, Nematicide, Aspergillus sp.
}

\section{Introduction}

We have previously investigated fungal metabolites such as aspyrone (Kimura et al., 1996), peniprequinolone (Kusano et al., 2000), $\beta \gamma$-dehydrocurvularin (Kusano et al., 2003), and penipratynolene (Nakahara et al., 2004) for their potential to act as nematicides against the root-lesion nematode Pratylenchus penetrans, which is a parasite of many crop plants and causes root necrosis (Pitcher et al., 1963; Towshend, 1963). In addition, Japanese black pine (Pinus thunbergii Parl.) and Japanese red pine ( $P$. densiflora Sieb. et Zucc.), the main species in Japan, have the highest susceptibility to pine wilt disease caused by the pine wood nematode Bursaphelenchus xylophilus (Fukuda, 1997; Kuroda et al., 1991). Plant-parasitic nematodes cause crop losses that have been estimated to be $9 \%$ of the world's crop yield each year. Conventional control methods are currently based on the use of low-specific biocidal compounds acting as nerve poisons, like carbamates, halogenated organic compounds. Some of those compounds cause global environmental problems. Methyl bromide has a destructive effect on the ozone layer, and its production is being restricted (Gonzalez and Estevez-Braun, 1997). Since it was necessary to develop effective nematicides with low risk for humans and wildlife, we have focused our attention on new nematicides from fungal metabolites that are valuable natural resources for agrochemical development, and we found the presence of the regulators in the culture filtrate of Aspergillus sp. Our investigation for metabolites of this fungus has now led to the isolation of one active substance, 5-hydroxymethyl-2-furoic acid (1). The present paper describes the production, isolation, structural determination, and biological activities of $\mathbf{1}$.

\section{Material and Methods}

\section{General experimental procedures}

Melting point was determined using a Yanagimoto micromelting point apparatus and is uncorrected. The UV spectrum was recorded on a SHIMAZU UV-2200 spectrophotometer and the IR spectrum on a JASCO FT IR-7000 spectrometer. The ${ }^{1} \mathrm{H}$ and ${ }^{13} \mathrm{C}$ NMR spectra were recorded with a JEOL JNM-ECD 500 NMR spectrometer at 500 and $125 \mathrm{MHz}$, respectively. Chemical shifts are expressed in $\delta$ values with solvents as internal standards. HREIMS datum was obtained with a JEOL JMS-SX 102 mass spectrometer. Silica gel (Wako Pure Chemical Industries, Ltd., 75$150 \mu \mathrm{m})$ was used for column chromatography. Precoated silica gel plates (Merck, Kieselgel 60 $\mathrm{F}_{254}, 0.2 \mathrm{~mm}$ ) were used for preparative TLC. 3Nitropropionic acid (3-NPA), purchased from Sigma-Aldrich Chemical Company, USA, was employed as a positive control. 


\section{Fungal material and fermentation}

Aspergillus sp. was collected from the soil in the city of Kitakyushu in April 2000. A voucher specimen (No. S328) is deposited at the laboratory of Bioorganic Chemistry, Department of Biological and Environmental Chemistry, Faculty of Agriculture, Tottori University. One hundred twenty 500$\mathrm{ml}$ Erlenmeyer flasks, each containing $250 \mathrm{ml}$ of malt extract medium supplemented with $3 \%$ polypeptone, were individually inoculated with $1-\mathrm{cm}^{2}$ agar plug taken from a stock culture of the fungus maintained at $20^{\circ} \mathrm{C}$ on potato dextrose agar. The fungus was statically grown at $24^{\circ} \mathrm{C}$ for $14 \mathrm{~d}$.

\section{Extraction and isolation}

The culture broth (30 1) was filtered, and the filtrate was adjusted to $\mathrm{pH} 2.0$ with $4 \mathrm{M} \mathrm{HCl}$ solution. The filtrate was successively extracted with EtOAc and concentrated in vacuo. The resulting residue $(2.9 \mathrm{~g})$ was first fractionated by column chromatography on silica gel ( $n$-hexane/acetone). The fraction $(1.08 \mathrm{~g})$, obtained by elution with $n$-hexane/acetone $7: 3$, was further purified by column chromatography on silica gel (benzene/acetone). The fraction $(0.72 \mathrm{~g})$, obtained by elution with benzene/acetone $7: 3$, was further purified by column chromatography on silica gel (benzene/acetone). The fraction $(0.14 \mathrm{~g})$, obtained by elution with benzene/acetone $9: 1$, was purified by preparative TLC ( $n$-hexane/EtOAc, 3:7, v/v). The fraction $(33 \mathrm{mg})$ was further purified by preparative TLC $\left(\mathrm{CHCl}_{3} / \mathrm{MeOH}, 9: 1, \mathrm{v} / \mathrm{v}\right)$ to afford $17 \mathrm{mg}$ of 1.

5-Hydroxymethyl-2-furoic acid (1): M. p. 114$115^{\circ} \mathrm{C}$. $-\mathrm{UV} / \mathrm{vis}(\mathrm{EtOH}): \lambda_{\max }(\lg \varepsilon)=252(3.90)$, $292 \mathrm{~nm}$ (3.21). - IR (KBr): $v=3292(\mathrm{OH}), 2962$ $(\mathrm{C}=\mathrm{C}), 2530(\mathrm{COOH}), 1657(\mathrm{O}-\mathrm{C}=\mathrm{O}), 1528 \mathrm{~cm}^{-1}$ $(\mathrm{C}=\mathrm{C}) .-{ }^{1} \mathrm{H}$ NMR $\left(500 \mathrm{MHz}\right.$, acetone- $\left.d_{6}\right): \delta=$ $4.60\left(\mathrm{~s}, 2 \mathrm{H}, 5-\mathrm{CH}_{2} \mathrm{OH}\right), 6.48(\mathrm{~d}, J=3.4 \mathrm{~Hz}, 1 \mathrm{H}, 4-$ $\mathrm{H}), 7.16(\mathrm{~d}, J=3.4 \mathrm{~Hz}, 1 \mathrm{H}, 3-\mathrm{H}) .-{ }^{13} \mathrm{C}\left\{{ }^{1} \mathrm{H}\right\} \mathrm{NMR}$ $\left(125 \mathrm{MHz}\right.$, acetone- $\left.d_{6}\right): \delta=57.4\left(\mathrm{t}, 5-\mathrm{CH}_{2} \mathrm{OH}\right)$, 109.6 (d, C-4), 119.5 (d, C-3), 145 (s, C-2), 159.7 (s, C-5), 160.9 (s, 2-COOH). - HREIMS: $m / z\left(\mathrm{M}^{+}\right)$: calcd. for $\mathrm{C}_{6} \mathrm{H}_{6} \mathrm{O}_{4}$ 142.0266; found 142.0268.

\section{Bioassay for nematicidal activity against Pratylenchus penetrans}

Nematicidal activities were measured in microwell plates with the root-lesion nematode Pratylenchus penetrans according to the method of Kusano et al. (2000). P. penetrans was cultured for about 2 weeks on a slant of alfalfa grown in Krusberg medium. The cultured nematodes were separated from the callus by the Baermann funnel technique and counted under a microscope. An aqueous suspension containing a definite number of nematodes (about 500 nematodes $/ \mathrm{ml}$ ) was prepared by dilution. Test compounds and extracts were dissolved in methanol and added to the nematode suspension (up to $3 \%$ volume of the suspension). The nematode suspension thus prepared was transferred to 24-well plates with wells containing a definite amount of the test compound. While plates were kept at $24{ }^{\circ} \mathrm{C}$ for $14 \mathrm{~d}$, nematodes in the wells were counted under a microscope once in $2 \mathrm{~d}$ for a total of 6 measurements from $4 \mathrm{~d}$ after treatment. The nematicidal activity is expressed as follows: mortality $(\%)=[(\mathrm{B}-\mathrm{A}) / \mathrm{B}] \times$ 100 , where $\mathrm{A}$ is the number of nematodes alive after being treated with the test compound, and B is the number of nematodes alive in the control wells ( $3 \%$ methanol in distilled water).

\section{Bioassay for nematicidal activity against Bursaphelenchus xylophilus}

Nematicidal activities were measured in microwell plates with the pine wood nematode Bursaphelenchus xylophilus. B. xylophilus was cultured for about 2 weeks on a slant of Botrytis cinerea grown in potato-dextrose medium. Separation of the cultured nematodes and the measurement of the nematicidal activity were carried out according to the method of Kusano et al. (2000).

\section{Bioassay for nematicidal activity against Caenorhabditis elegans}

Nematicidal activities were measured in microwell plates with the free-living nematode Caenorhabditis elegans according to the method of Kusano et al. (2000). Worms were cultivated on agar plates as described previously. For the assay, a suspension of adults and L4 larvae (more than 90\%) from a 4-day-old culture was diluted with M9 buffer to a solution containing a definite number of nematodes (about 500 nematodes $/ \mathrm{ml}$ ). Test compounds and extracts were dissolved in $0.2 \mathrm{ml}$ of $3 \%$ methanol. The nematode suspension $(0.1 \mathrm{ml})$ thus obtained was added to 24 -well plates with wells containing a definite amount of the test compound. After plates were kept at $18^{\circ} \mathrm{C}$ for $2 \mathrm{~d}$, the measurement of the nematicidal activity was carried out according to the method of Kusano et al. (2000). 
Bioassay for the growth of lettuce, carrot, and raddish seedlings

Lettuce (Lactuca sativa cv. Kingcisco), carrot (Daucus carota cv. Benikoshigosun), and raddish (Raphanus sativus Linn. cv. Frenchbreakfast) seeds were purchased from Takii Nursery and sown in a Petri dish $(150 \times 25 \mathrm{~mm})$ lined with a filter paper containing deionized water. After $1 \mathrm{~d}$ under continuous light $\left(100 \mu \mathrm{E} / \mathrm{m}^{2} \mathrm{~s}\right)$ at $24^{\circ} \mathrm{C}$, seedlings were selected for uniformity (radicles; $2 \mathrm{~mm}$ ) and transferred into a mini-Petri dish $(35 \times 15 \mathrm{~mm})$ lined with filter paper containing $1 \mathrm{ml}$ of deionized water and a defined amount of the test compound. The Petri dish was kept at $24{ }^{\circ} \mathrm{C}$ for $4 \mathrm{~d}$ under continuous light $\left(100 \mu \mathrm{E} / \mathrm{m}^{2} \mathrm{~s}\right)$. The length of the hypocotyls and roots treated with the compound was measured and the mean value of the length was compared with an untreated control (Kusano et al., 1998). Triplicate experiments were conducted.

\section{Bioassay for the growth of rice and barnyard millet seedlings}

Rice (Oryza sativa L. cv. Nihonbare) and barnyard millet (Echinochloa esculenta cv. Shirohie) seeds were sterilized with $75 \%$ ethanol for $30 \mathrm{~s}$, immersed in sodium hypochlorite solution (antiformin) for $2 \mathrm{~h}$, rinsed under running water for $3 \mathrm{~h}$, and transferred to a Petri dish $(150 \times 25 \mathrm{~mm})$ containing deionized water. After $3 \mathrm{~d}$ under continuous light $\left(100 \mu \mathrm{E} / \mathrm{m}^{2} \mathrm{~s}\right)$ at $30^{\circ} \mathrm{C}$, seven seedlings were selected for uniformity (radicles; $2 \mathrm{~mm}$ ) and transferred into a test tube $(35 \times 15 \mathrm{~mm})$ containing $1 \mathrm{ml}$ of deionized water and a defined amount of the test compound. The test tube was sealed with a polyethylene film and incubated for $7 \mathrm{~d}$ under continuous light $\left(100 \mu \mathrm{E} / \mathrm{m}^{2} \mathrm{~s}\right)$ at $30^{\circ} \mathrm{C}$. The total length and the lengths of the second leaf sheath and primary root after treatment with the compound were measured and the mean lengths were compared with an untreated control (Kusano et al., 1998). Triplicate experiments were conducted.

\section{Results and Discussion}

The EtOAc-soluble acidic fraction (2.9 g) from the filtrate of Penicillium sp. was purified by silica gel column chromatography and preparative TLC to afford $\mathbf{1 .}$

Compound $\mathbf{1}$ was obtained as colorless needles. The molecular formula of $\mathbf{1}$ was established as $\mathrm{C}_{6} \mathrm{H}_{6} \mathrm{O}_{4}$ by HREIMS. The ${ }^{1} \mathrm{H}$ and ${ }^{13} \mathrm{C}$ NMR spec-

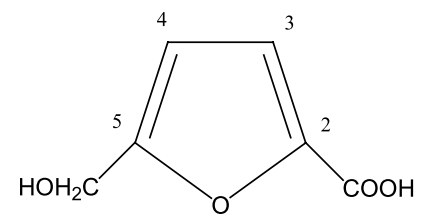

Fig. 1. Structure of 5-hydroxymethyl-2-furoic acid (1).

tra, and PFG-HMQC experiments indicated the presence of one O-substituted aliphatic carbon atom, two aromatic methine carbon atoms, two Osubstituted aromatic quarternary carbon atoms, one carbonyl group. The IR absorption band at $3292 \mathrm{~cm}^{-1}$ indicated the presence of a hydroxy group. The IR absorption band at $2962 \mathrm{~cm}^{-1}$ and a signal at $\delta 160.9$ in the ${ }^{13} \mathrm{C}$ NMR spectrum indicated the presence of a carboxy group. Detailed
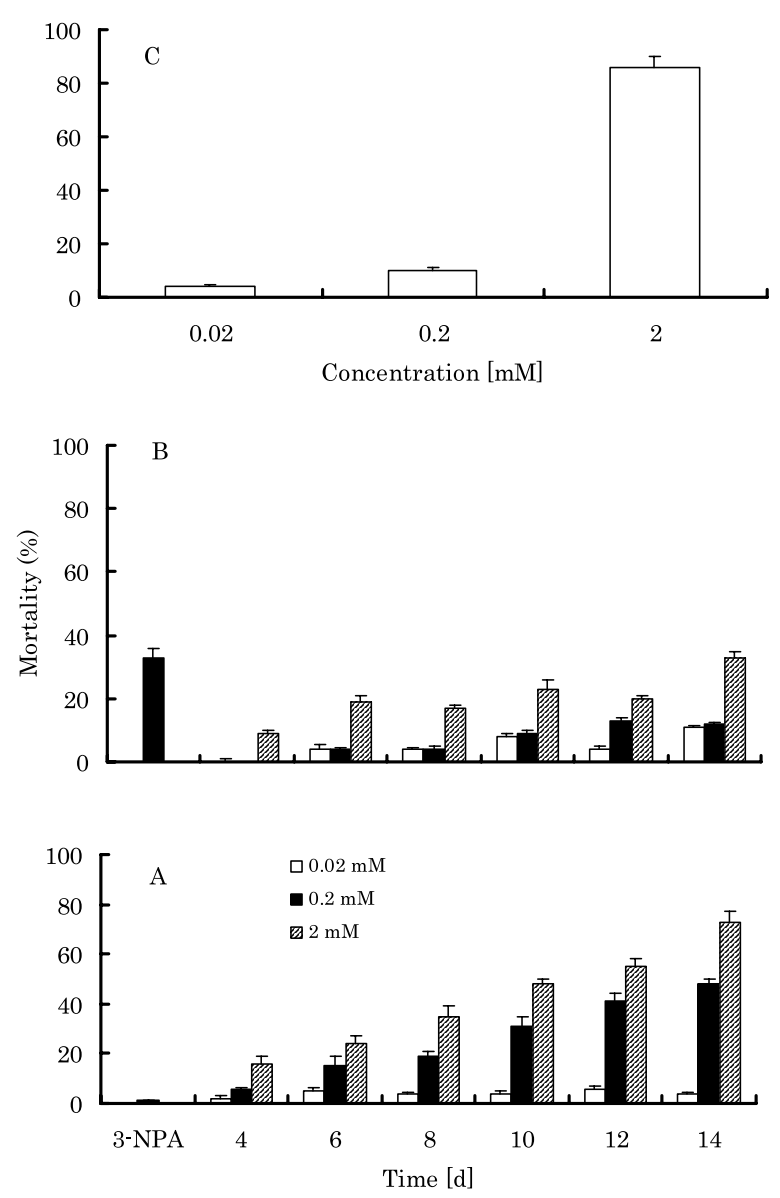

Fig. 2. Nematicidal activities of $\mathbf{1}$ against Bursaphelenchus xylophilus (A), Pratylenchus penetrans (B), and Caenorhabditis elegans (C). 

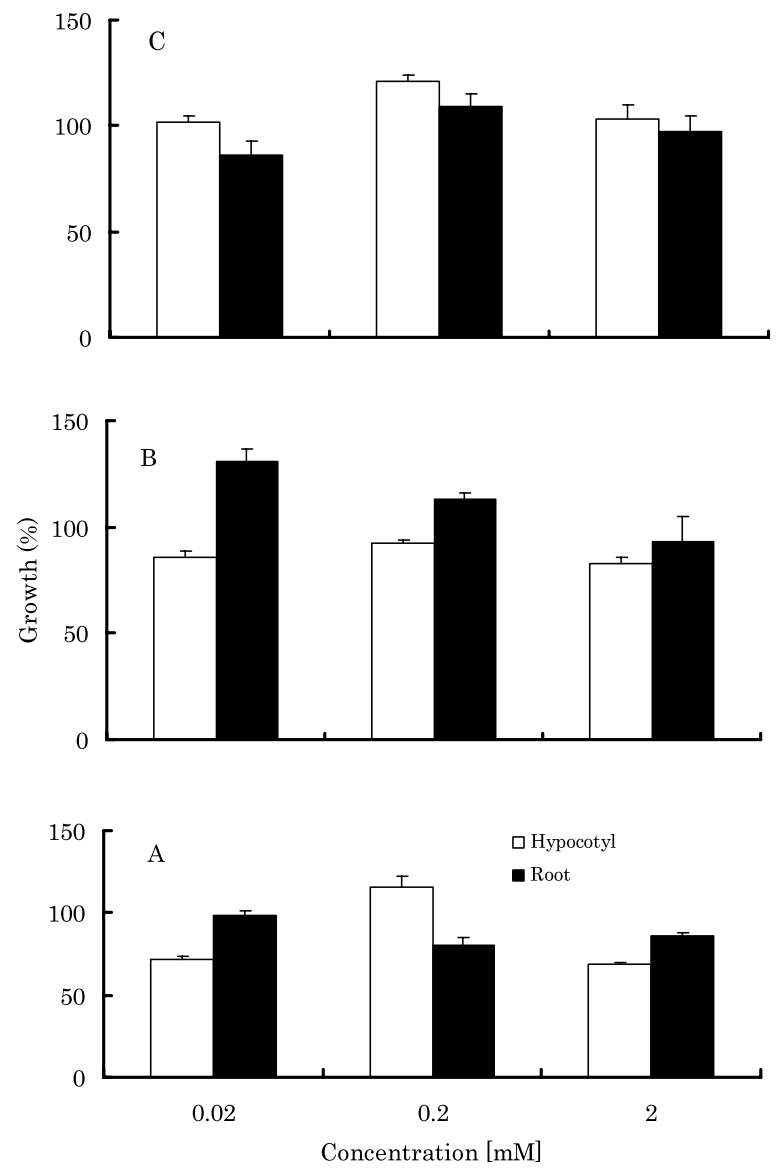

Fig. 3. Plant growth activities of $\mathbf{1}$ against lettuce (A), carrot (B), and raddish (C) seedlings.

analysis of PFG-HMBC experiments led to the structure of 1 (Fig. 1). From those results, 1 was identified as 5-hydroxymethyl-2-furoic acid (Fig. 1) by comparing the physicochemical properties with those reported (Munekata and Tamura, 1981).

This is the first report on the nematicidal and plant growth activities of $\mathbf{1}$. Compound $\mathbf{1}$ is known to show cytotoxic activity against SV40-transformed cells in vitro and slightly effective antitumor activity against Sarcoma 180 in vitro (Munekata and Tamura, 1981).

The nematicidal activities of $\mathbf{1}$ were examined against $P$. penetrans, B. xylophilus, and C. elegans. Compound $\mathbf{1}$ had a weak nematicidal activity against $P$. penetrans of $8 \%$ at a concentration of $2 \mathrm{~mm}$ after 4 days of incubation, but 1 had no nematicidal activity at the concentrations of $0.02 \mathrm{~mm}$ and $0.2 \mathrm{~mm}$. Compound 1 had weak nem- aticidal activities of $11 \%, 12 \%$, and $33 \%$ at the concentrations of $0.02 \mathrm{~mm}, 0.2 \mathrm{~mm}$, and $2 \mathrm{~mm}$ after 14 days of incubation, respectively. Compound 1 showed nematicidal activity similar to that of $2 \mathrm{~mm}$ 3-nitropropionic acid (Fig. 2). Compound 1 had nematicidal activity against B. xylophilus of $2 \%$, $6 \%$, and $16 \%$ at the concentrations of $0.02 \mathrm{~mm}$, $0.2 \mathrm{~mm}$, and $2 \mathrm{~mm}$ after 4 days of incubation, respectively. Compound 1 also caused $4 \%, 48 \%$, and $73 \%$ mortality at the same three concentrations after 14 days of incubation, respectively. Compound 1 promoted nematicidal activity against $B$. xylophilus in proportion to its exposure time from 4 days to 14 days (Fig. 2). Compound 1 had nematicidal activities against C. elegans of $4 \%, 10 \%$, and $86 \%$ at the same three concentrations after 2 days incubation, respectively (Fig. 2).

Phytotoxic activities of $\mathbf{1}$ were examined against lettuce, carrot, raddish, rice, and barnyard millet seedlings. Compound $\mathbf{1}$ had no inhibitory activities against hypocotyl elongation and root growth of lettuce seedlings at a concentration of $0.02 \mathrm{~mm}$, but it showed weak inhibitory activities against root growth at the concentrations of $0.2 \mathrm{~mm}$ and $2 \mathrm{~mm}$ (Fig. 3A). It promoted root growth of carrot seedlings at a concentration of $0.02 \mathrm{~mm}$, but 1 did not show any promotive activity against the root
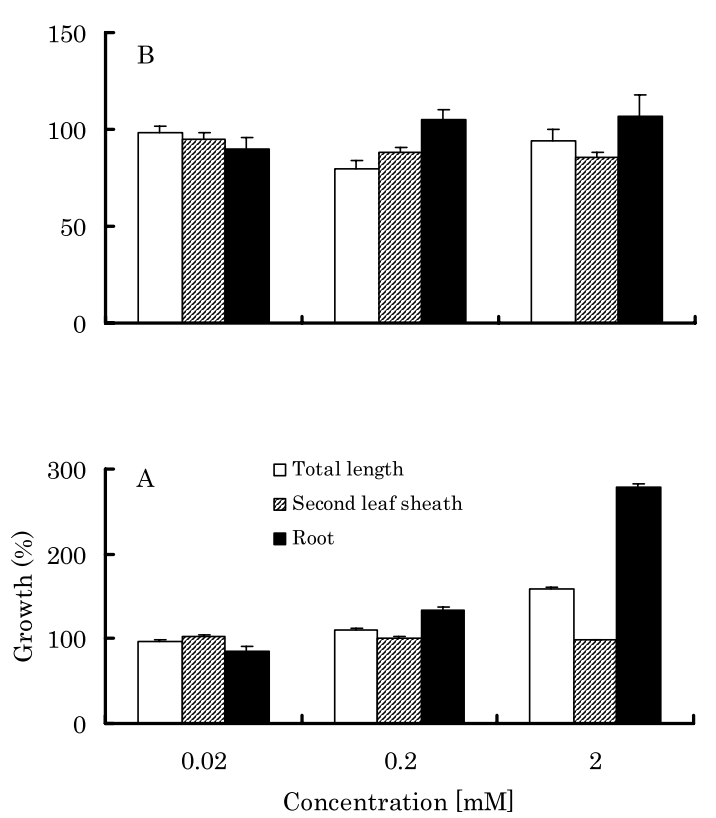

Fig. 4. Plant growth activities of $\mathbf{1}$ against rice (A) and barnyard millet (B) seedlings. 
growth at the concentrations of $0.2 \mathrm{~mm}$ and $2 \mathrm{~mm}$, respectively (Fig. 3B). Compound $\mathbf{1}$ had no inhibitory activities against the hypocotyl elongation and root growth of raddish seedlings (Fig. 3C). Compound 1 promoted total length and root growth of rice seedlings at the concentrations of $0.2 \mathrm{~mm}$ and $2 \mathrm{~mm}$, and total length at $2 \mathrm{~mm}$ (Fig. 4A). Compound $\mathbf{1}$ had no inhibitory activity against the growth of barnyard millet seedlings (Fig. 4B).

Bird A. F. (1958), The adult female cuticle and egg sac of the genus Meloidogyne Goeldi, 1887. Nematologica 3, 205-212.

Ellenby C. (1946), Nature of the cyst wall of the potatoroot eelworm Heterodera rostochiensis, Wollenweber, and its permeability to water. Nature 157, 302-303.

Fukuda K. (1997), Physiological process of the symptom development and resistance mechanism in pine wilt disease. J. For. Res. 2, 171-181.

Gonzalez J. A. and Estevez-Braun A. (1997), Phytonematicidal activity of aromatic compounds related to shikimate pathway. Pestic. Biochem. Physiol. 58, 193-197.

Kimura Y., Nakahara S., and Fujioka S. (1996), Aspyrone, a nematicidal compound isolated from the fungus, Aspergillus melleus. Biosci. Biotechnol. Biochem. 60, $1375-1376$.

Kuroda K., Yamada T., and Ito S. (1991), Bursaphelenchus xylophilus induced pine wilt: Factors associated with resistance. Eur. J. For. Path. 21, 430-438

Kusano M., Sotoma G., Koshino H., Uzawa J., Chijimatsu M., Fujioka S., Kawano T., and Kimura Y. (1998), Brevicompanines A and B: new plant growth regulators produced by the fungus, Penicillium brevicompactum. J. Chem. Soc. Perkin Trans. 1, 2823-2826.
Compound 1 showed effective nematicidal activities against B. xylophilus and C. elegans without inhibitory activity against plant growth, but $\mathbf{1}$ did not show any effective nematicidal activity against $P$. penetrans. The difference in nematicidal activities of 1 against the three test nematodes might be attributed to the chemical composition and the permeability to water of their cuticles (Ellenby, 1946; Bird, 1958).

Kusano M., Koshino H., Uzawa J., Fujioka S., Kawano T., and Kimura Y. (2000), Nematicidal alkaloids and related compounds produced by the fungus Penicillium cf. simplicissimum. Biosci. Biotechnol. Biochem. 64, 2559-2568.

Kusano M., Nakagami K., Fujioka S., Kawano T., Shimada A., and Kimura Y. (2003), $\beta \gamma$-Dehydrocurvularin and related compounds as nematicides of Pratylenchus penetrans from the fungus Aspergillus sp. Biosci. Biotechnol. Biochem. 67, 1413-1416.

Munekata M. and Tamura G. (1981), Antitumor activity of 5-hydroxymethyl-2-furoic acid. Agric. Biol. Chem. 45, 2149-2150.

Nakahara S., Kusano M., Fujioka S., Shimada A., and Kimura Y. (2004), Penipratynolene, a novel nematicide from Penicillium bilaiae Chalabuda. Biosci. Biotechnol. Biochem. 68, 257-259.

Pitcher R. S., Patrick Z. A., and Mountain W. B. (1963), Studies on the host-parasite relations of Pratylenchus penetrans (Cobb) to apple seedlings. Nematologica $\mathbf{5}$, 309-314.

Towshend J. L. (1963), The pathogenicity of Pratylenchus penetrans to celery. Can. J. Plant Sci. 43, 70-74. 